\title{
Guía Práctica Clínica: Hipertensión arterial: posición del Instituto Nacional de la Salud y la Excelencia Clínica (NICE) del Reino Unido de Gran Bretaña (2006)
}

\begin{abstract}
Resumen
En este artículo se resumen y comentan el meta-análisis que comparó "cabeza a cabeza" los fármacos antihipertensivos de uso más frecuente y las principales recomendaciones de la guía inglesa publicada por el Instituto Nacional de la Salud y la Excelencia Clínica (en inglés NICE) del Reino Unido de Gran Bretaña en 2006.

Explicitando la fuerza de la recomendación según la calidad de la evidencia que la respalda, esta guía refuerza la estrategia de tratamiento de la hipertensión arterial considerando el riesgo cardiovascular global de cada paciente, la importancia de los cambios en el estilo de vida, sugiere diferentes abordajes según la edad y/o el origen étnico e intenta sistematizar un algoritmo escalonado de tratamiento.
\end{abstract}

La tabla 1 resume los grados de evidencia y la fuerza de las recomendaciones en las que se basa esta guía y que aparecen entre paréntesis a lo largo del texto de la misma.

Tabla 1: grados de evidencia y fuerza de las recomendaciones en las que se basa esta guía.

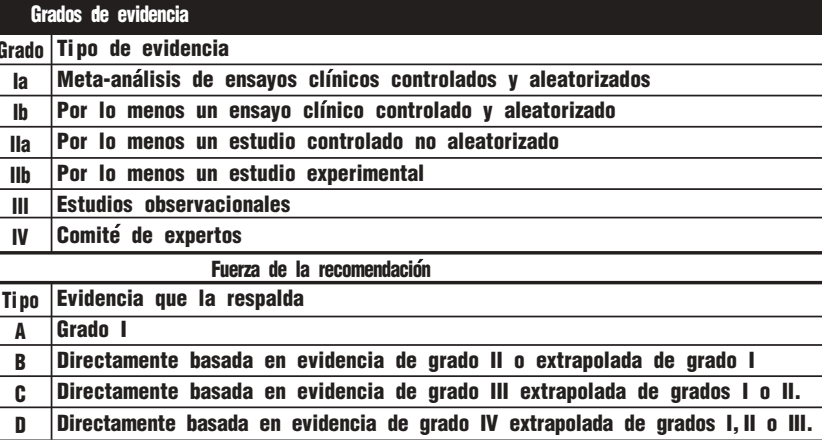

\section{Medida de la presión arterial}

Se recomienda que la tensión arterial (TA) sea tomada por personas entrenadas (D).

Ante un registro hipertensivo y para identificar la condición clínica "hipertensión arterial" (elevación persistente de la presión arterial por encima de $140 / 90 \mathrm{mmHg}$ ) se debe invitar al paciente a volver, al menos, a dos consultas posteriores en las que se valorará la tensión arterial en dos tomas y en las mejores condiciones posibles (ambiente relajado, cálido y tranquilo, con el paciente sentado con el brazo extendido y apoyado). Si la primera medida es mayor $140 / 90 \mathrm{mmHg}$, confirmarla al final de la consulta. Tomar la TA en ambos brazos y elegir como referencia en futuras visitas al valor más alto (D).

Si el paciente tiene hipotensión postural y/o caídas ó mareos, tomarla de pié, para identificar la hipertensión arterial (HTA) definida como persistencia de valores superiores a $140 / 90 \mathrm{mmHg}$ (D). Si la HTA es severa, reevaluar la presión como mínimo mensualmente (D).

No se recomienda rutinariamente los registros domiciliarios, ni los de medición continua (Holter) debido a que los valores no han sido adecuadamente consensuados (C)

\section{Criterios de derivación}

Derivar inmediatamente a un centro de mayor compleiidad ante: - Hipertensión maligna: TA mayor a $180 / 110 \mathrm{mmHg}$ con papiledema y/ó hemorragias retinianas. (D).

- Sospecha de feocromocitoma: hipotensión postural, cefalea, palpitaciones, palidez y sudoración (D)

Considerar la derivación si hay signos y síntomas inusuales, manifestaciones sugerentes de causa secundaria, hipotensión postural ó caída de la presión sistólica superior a $20 \mathrm{mmHg}$ al ponerse de pié.

\section{Intervenciones sobre el estilo de vida}

Los consejos sobre el estilo de vida deberían recomendarse desde la primera consulta y periódicamente durante la valoración ó tratamiento de la hipertensión.

\section{Medidas para reducir la presión arterial}

Interrogar sobre los patrones dietéticos y de ejercicio y proporcionar guías ó información escrita ó audiovisual (B) ya que los consejos multifactoriales sobre el estilo de vida reducen la presión arterial entre 4 y $5 \mathrm{mmHg}$.

Un tercio de los pacientes que realizan terapias de relajación reduce la TA en $10 \mathrm{mmHg}$ o más en el término de un año. Si incluyen manejo del stress, meditación, terapias cognitivas, yoga, etc; pueden reducir la TA en pacientes individuales como parte de su tratamiento. Sin embargo, no se recomiendan de rutina en el ámbito de la atención primaria (B)

Preguntar sobre el consumo de alcohol y aconsejar reducción si es excesivo (B).

Disuadir del consumo excesivo productos ricos en cafeína (C).

Estimular la reducción del consumo de sal y/o el uso de sustitutos (B).

No ofrecer suplementos de calcio, magnesio o potasio para reducir la TA (B).

Consejo sobre abandono del tabaco (A).

Informar sobre iniciativas locales que ayuden a proporcionar y promocionar estilos de vida saludables, como equipos de salud ú organizaciones de pacientes, o programas crónicos de enfermedades prevalentes (D).

\section{Riesgo Cardiovascular}

Si persiste aumentada la presión arterial y el paciente no tiene enfermedad cardiovascular establecida, acordar con él la necesidad de valorar su riesgo cardiovascular. Los exámenes complementarios pueden ayudar a identificar diabetes, evidencia de daño de órgano blanco y causas de hipertensión secundaria como la enfermedad renal (D).

Realizar un electrocardiograma, pesquisar proteinuria, y valorar la glucemia, el colesterol total y HDL, los electrolitos y la creatininemia (D).

Estimar el riesgo cardiovascular ${ }^{1,2,3}$ a través de alguna de las reglas de predicción clínica* para discutir con el paciente su pronóstico y las opciones terapéuticas, tanto para reducir la TA como para realizar cambios de hábitos de vida que impliquen la mejoría de los factores de riesgo modificables (D). 